International Journal of English Literature and Social Sciences
Vol-6, Issue-6; Nov-Dec, 2021

Peer-Reviewed Journal

\title{
Alienated Suffering of Divide and Cross: A Study of Amitav Ghosh's The Shadow Lines
}

\author{
Dr. Mohd Farhan Saiel
}

Assistant Professor, Department of Languages, Integral University, Lucknow, U.P. India

Received: 03 Oct 2021; Received in revised form: 05 Nov 2021; Accepted: 12 Nov 2021; Available online: 18 Nov 2021

(C2021 The Author(s). Published by Infogain Publication. This is an open access article under the CC BY license

(https://creativecommons.org/licenses/by/4.0/).

\begin{abstract}
This article attempts to examine the melancholy and sadness of nostalgic feelings and alienated sufferings of divisional and cross of the nation. The novel deals with the partition of India, is the subject of many Indian, Pakistani and Bangladeshi writers. Some of them were the direct victims of the event while others have the inherited the legacy of Partition from different members of their family, friends and community. In fact, the people of South Asia are still occupied with the partition and the attitude of many generations to history suggests something never to be forgotten. The writers of the Partition have focused on various issues like violence, migration, alienation, nostalgia, rape, abduction etc. The attempt in this paper is to read out displacement, nostalgia, and alienated sufferings in context of Amitav Ghosh's The Shadow Lines. The Partition and the creation of the border have formed the politics of the continent as well as the thinking of its people. Amitav Ghosh deals the subject of border as futile and false lines. The study focuses on how the protagonist of the novel deals with these lines showing their sufferings through alienation and nostalgic emotions to what extent they shape the psyche of different characters. Since Amitav Ghosh speaks up from West Bengal, and is the second generation to experience partition through stories, beautifully describes the context of Bengal and the meaning of the Partition to different generations. The paper also focuses on the theme of exile or sense of belongingness, the partition of India, and consequent of trauma of the East Bengal's psyche.
\end{abstract}

Keywords-Partition, Alienation Sufferings, Nostalgia, Border Cross, and Division.

Partition as a term generally refers to the division of space, and within geo-political context, it according to the Cambridge Dictionary refers to "the dividing of a country into separate countries or areas of government. Partition in its specific geo-political context thus has far-reaching implications on regional, national and global politics. Despite stemming from, or rooted in ideological, ethnic or cultural differences amongst communities living together, Partitions are always an outcome as well as a cause" (Jassal \& Ben-Ari 2007). It Often executed in order to end existing struggles or to separate two warring parties, partitions in turn open up new arenas of dissent and lead to further conflict, be it in form of power struggle within the newly created nation, or the continuation of conflict with the neighbouring regions from which the partition took place, the most notable example being India, Pakistan and Bangladesh.

The Shadow Lines deals with the border studies, conflict studies, history, and political studies and also in literary studies. The significance of Partition literature lies in the fact that it moves beyond the sole political implications of Partition and focuses on its metaphoric, symbolic and mnemonic relevance. The fictive narratives of Partition offer an insight into how major national events can be remembered and re-envisaged in a personal and reflexive mode. Partition narratives are not primarily about the reiteration of historical events as undertaken by historiographical accounts. Literary Partition narratives 
represent non-standardized versions of Partition that often stands in disjunction with an otherwise one-dimensional and often heavily censored (national) version of an historical event, which in actuality is characterized by its diverse dimensions and narratives. Artistic portrayals of Partition, be it in form of literature or films, exemplify the plurality of Partition experiences.

The artistic description of the Partition of India and Bangladesh in Amitav Ghosh's novel The Shadow Lines brings into renown the plurality of human experiences. It also contests the arbitrariness of a nation and explores in-depth issues of nostalgia, alienated sufferings, class, gender, religion, displacement, and the meaning of existence. The vulnerability of humanity and truncation are willing to stoop to come alive in the novel, once again urging to assess the concept of alienation and displacement itself.

The novel is an amalgamation of history, the studies of conflict, border, and politics. It interrogates the questions about the sufferings and nostalgic feelings of homelessness that had never left their respective community were suddenly forced to pick one nation over another and migrate to lands unknown, leaving behind their kith and kin and everything they hold their near and dear ones. While this novel humanizes the anguish of the ones who got removed from their places of worship, who boarded trains hoping to reach "home" only to lose their lives to mass hysteria, and those who had to turn against their beloved neighbours to survive.

Amitav Ghosh, one of the foremost and the prominent voices of Indian Writings in English, has no faith and belief in national borders and geographical boundaries that divide and separate both the country and its people from their own people as well as from other neighbouring countries and their people under the pretext of religion and community. Ghosh in his novel, sees history as that trajectories of events that causes dislocations, disjunctions, movements and migrations, eventually replacing solid markers with shadow lines, destabilizing our nations of the past in the reverberations of the present (Bose 2003).

The Shadow Lines depicts the suffering, the death, alienation, nostalgia and the devastation caused by a shadow line of division that could not reverse the shadow line of connection. In the novel, the past merges fluidly with the present as it reflects the restlessness and turmoil of the times and its meaning in the present context. The novel deals with the history of World War II, the freedom movements, the partition and the subsequent communal outbreak. Amitav Ghosh explores the agony of alienation and the meaning of contemporary India, the cross cultural friendship and feelings.

It is a historical novel that focuses mostly on nationalism, identity, pangs of characters and the meaninglessness of partition and the 1964 communal riots which occurred in Calcutta, Dhaka and Khulna. This article attempts to investigate The Shadow Lines from the perspective of division of nation to reflect on the negative impact on peoples' minds because of political uncertainties. Ghosh's The Shadow Lines chronicles three generations in a family saga that spreads over Dhaka, Calcutta and London. The book has two sub-sections: Going Away and Coming Home. Both phrases indicate the queer sense of home and homelessness that the partition victims have experienced that allows them to dispense with a fixed point that signifies a point of departure. In the first section, the narrator draws the picture of a war that reveals the pangs and sufferings of the people. He relates the story of his family members and narrates that how they came to London and also depicts the family harmony between the Prices and Mayadebi whose son Tridib enchants the narrator with his story telling and in-depth knowledge of many places. A love relationship between Tridib and May Price, the daughter of the Prices, develops when May returns to Calcutta. The narrator learns about the war from Tridib, his gifted uncle. In the second section of The Shadow Lines, Ghosh pays attention to communal strife in Calcutta and Dhaka caused by the loss of the Prophet's hair from Hazratbal shrine, Srinagar.

The story deals with the lives of two different families, one an Indian family and the other, an English family. This sort of story-structure questions the boundaries between the people and the geographical setting that they inhabit. The story shifts from London to Calcutta to Dhaka is told through the point of view of a contemporary Indian male, although the real luminaries of the plot are the young man's grandmother and his cousin named Tridib. The stories interweave life in Dhaka before Partition, life in London during the war and the life of the narrator leads in Calcutta during the 1960s and his life in London of the 1970s. The anonymous narrator recounts in flashback about the people and places which were described to him by his uncle Tridib twenty years before and the heady life of modern London that signified the centre of the Universe. It is an undeniable fact that the narrator considers his imaginary reconstructions of the past as more real than that of the present. It is because he lives through the stories of other people. He strongly believes that the actual present alone can serve as an impulse for the narrative construction of memories. His outlook of life is quite contrary to that of his cousin; Ila who treats the 
actual present alone is the real one. Unlike the narrator, she does not take refuge in the past.

The Shadow Lines spans three generations of the narrator's family spread over Calcutta, Dhaka, London, and his English family friends, the Prices. The novel is written against the backdrop of the civil strife in the postpartition East-Pakistan and riot-hit Calcutta, the narration of the incidents begins in 1939 (the year World War II broke out) and ends in 1964. Robi, one of the narrator's cousins, describes his experiences at the time of acting as a government official:

I'd have to go out and make speeches to my policemen saying: You have to be firm; you have to do your duty. You have to kill whole villagers if necessary - we have nothing against the people, it's the terrorists we want to get, but we have to be willing to pay a price for our own unity and freedom. And I went back home, I would find an anonymous note waiting for me saying: We're going to get you for our freedom. It would be like reading my own speech transcribed on a mirror (Amitav Ghosh 246-247).

Ironically, both the terrorists and the government troops are acting to secure their freedom, which, as a construction of nationalist ideology, is only an illusion. Thus, with the eruption of a cycle of violence both in India and EastPakistan, his boyhood experiences during wartime London and his violent death twenty five years later in Dhaka constitute the end point of the novel's essential narrative.

The events revolve around Mayadebies' family, their friendship, residence with the English friends and Thamma, the narrator's grandmother's links with Dhaka, her ancestral city. The novel takes us into mnemonic fund of a young narrator who as a wide-eyed adolescent, heroworshipped his uncle, Tridib, who fed him on the memories of his one visit to London during the war and Thamma his grandmother, who shared with him her nostalgia of East Bengal where she was born and spent her childhood. And then there is Ila, the daughter of Tridib's elder brother, who travels all over the world with her diplomat globe-trotting parents and occasionally comes home to tell the wonderstruck boy the account of her peregrinations abroad. While the narrator's experience is travelling in the mind through imagination, Ila's experience of travelling is based on the actual travelling in person through reality. The narrator acknowledges that he has created his own secret map of the world. Their memories, says the narrator, "Form a part of my secret map of the world, a map of which only I know the keys and co-ordinates, but which was not for that reason any more imaginary than the code of a safe to a banker" (Amitav Ghosh 196).

The novel refers to the blurred lines between nations, land, and families as well as within one's own self-identity. Ghosh depicts the characters of the novel as caught between two worlds. Hence, they struggle to the core to come to terms with both their present as well as their past. Like Gandhi, Ghosh is opposed to the political discourse as well as the haphazard division of land and human communities that are required to form a nation. Ghosh's tale dramatizes the inner conflicts of the comparison of dissimilar yet related cultures as well as the outward conflicts between friends and families that have been inflicted by geopolitical discord.

The novel also provides an insight into the history of colonization legacies. The death of the main characters at the border is the realistic portrayal of the suffering of the people who have to endure the pangs of separation and the aftermath effect of it as they move between the borders of homeland. Said echoes Ghosh's opinion in Culture and Imperialism by describing imperialism as an act of geographical violence through which virtually every space in the world is explored, charted and finally brought under control (Said 4).

In the novel, the lives of the narrator's family have been irrevocably changed as a consequence of Bengal's Partition between India and Pakistan at the time of Independence and the subsequent experience of the East Pakistan Civil War of 1971, which led to the creation of Bangladesh. Towards the end, when members of the family are about to undertake a journey from Calcutta to their former home in Dhaka, the narrator's grandmother asks whether she will be able to see the border between India and East Pakistan from the plane. She is puzzled when told that there will be no such visible demarcation and says: "But if there aren't any trenches or anything, how are people to know? I mean, where's the difference then? And if there's no difference both sides will be the same; it'll be just like it used to be before, when we used to catch a train in Dhaka and get off in Calcutta the next day" (Amitav Ghosh).

This ingenuous response on her part highlights the absurdity of the revisionist map-making of the politicians responsible for Partition. Because the truth is that there really is no difference between this side of the border and that. There is nothing concrete about these borders for they only exist in maps and in our minds.

In proof of the meaninglessness of borders, the author gives us a glimpse of the reactions that shook Dhaka and Bengal on their separation. There was a striking 
similarity in the pattern of fear, mutual hatred and violence that gripped the two nations only the collective crimes were perpetrated on the opposite country's people. Thus, the division, the lines of demarcation actually brings the people of the two countries closer together through the mirroring of the people's reactions and through the similar and tragic deaths on both sides. In their mutual but laterally inverted reactions of violence, the two countries proved how much the same they were. The narrator realizes the futility of this incessant line-drawing by the politicians, for it never actually manages to separate anything or anyone but only provokes mindless acts of violence that in fact highlight the sameness of human emotions and perceptions, no matter which side of the border people are. In this context, Ghosh describes:

They had drawn their borders, believing in that pattern, in the enchantment of lines, hoping perhaps that once they had etched their borders upon the map, the two bits of land would sail away from each other ... What had they felt, I wondered, when they discovered that they had created not a separation, but a yet-undiscovered irony - the irony that killed Tridib: the simple fact that there had never been a moment in the fourthousand-year-old history of that map, when places like Dhaka and Calcutta were more closely bound to each other than after they had drawn their lines ... (Amitav Ghosh).

Tridib and the narrator do not believe in the concreteness of borders because they easily cross them with their imagination, bringing together different nations, cultures and ideals in their mind, the grandmother does firmly believe in these borders. In fact, she believes in them so fervently, perhaps defensively, that she disapproves of Ila, because Ila spent her entire life heedless of these borders, crossing them again and again in her travels to different countries. Grandmother says:

Ila has no right to live there, she said hoarsely. She doesn't belong there. It took those people a long time to build that country; hundreds of years, years and years of war and bloodshed. Everyone who has lived there has earned his right to be there with blood: with their brother's blood and their father's blood and their son's blood. They know they're a nation because they've drawn their borders with blood (Amitav Ghosh).

Sadly, most people have similar ideas about borders. These shadow lines are what they try to base their identity on. For them, shadow lines are more than just lines of demarcation, the frontiers constructed by politicians. They are to them the signifying acts that construct notions of discrete identity. The grandmother, too, bases her identity as an Indian, as distinct from a Bangladeshi, on the lines that separate India and Bangladesh. So firmly does she believe in them that she is disappointed with the lack of tangible lines that divide the two countries? Because she derives strength in her patriotism from her belief in these lines and the supposition that her identity is bound with them, her sense of identity is also shaken.

On the other hand, Ila's belief is that her internationalism can liberate her. She wants to be free of these lines that stifle her. So she lives in London with people and her belief will affect the history of the entire world, irrespective of boundaries and borders, and who, she is convinced, will free her too from these oppressive lines of demarcation. What is ironical is that the political activists with whom Ila shares her house in London "regard her as a kind of guest, a decoration almost and talk of her as our own upper-class Marxist" (Amitav Ghosh).

Furthermore, the striking disharmony between her intellectuality and nativity is reinforced by the following irony: it is never brought to her knowledge that her future husband Nick Price was ashamed to be seen by his friends, walking home with an Indian. She is thus stuck, even in London, as a stranger, those same lines that she ran away from pursuing her and marking her as an outsider. In what she centralizes as here, she is thus forced to act as another. For this reason, she is in no way free from the shadow lines, nor does she gain her personal freedom. Separation in The Shadow Lines is never a clean cut affair; it paradoxically turns out to be an extension, a continuation, something that is indivisible. The author brings forward to us the inhuman consequences of the creation of these shadow lines of demarcation. He reveals through the riots the absurd manner in which one's home can suddenly become one's enemy, when those people who cannot separate their identity from their belief in these borders develop and nurture hatred towards each other.

In 1964, due to the disappearance of holy hair relic from the Hazarat Bal Mosque in Kashmir Valley riots broke out in the region and many people breathed their last. When it was flashed in the dailies of Dhaka, the city had lost its tranquillity. People came out on the roads to brutally kill the innocents who were ignorant of all this. Tridib was one of such innocents who died for no faults of 
his own. Thus, his death becomes significant. The narrator tries to understand the sense of violence exploded in the wake of partition. In this way, partition was a great shock to the people of the time. Due to it, they had lost their relations of blood. They did not believe in the existence of the imaginary dividing shadow lines on the maps of the country. To them, it was the political administrators and designers who had created such lines for their selfish gains. Otherwise, the entire Hindustan had long been living in peace and harmony. Though people had different religions, they were living in mutual cooperation and collaboration. The political administrators had forced the country to undergo the evil experience of partition. Mr. M. A. Jinna was quite determined in his stand for the formation of Pakistan on the cause of religion. His claim had no vision behind it. Ultimately, his stand proved to be hazardous for in the riots broke out after partition it has been unofficially stated that about five lac people lost their lives during and after partition. But then the industrious people on both sides of the border lived peacefully. No doubt, there were gossips that their relatives are killed in the other parts and the people to suffer from such scandals were not the creators of borders. They were not the political administrators but working men on both sides. They did not even know who Mr. Jinna or Mr. Nehru was. They were unknown to the cause of partition too. That is why in the novel the old uncle of Thamma called Jethamoshai in Dhaka gives entry to a Muslim family who looks after him. Khalil of the Muslim family is a rikshaw driver. He looks after the old man more carefully than his own family. But both the innocent people i.e. the old man and Khalil are killed in the riots. These innocent people have an unqualified love for their motherlands irrespective of the borders drawn between them. The old uncle does not leave his old ancestral house in Dhakka. He loves his house and the city very much. He does not believe in the demarking lines between India and Pakistan. He says:

Once you start moving you never stop. That's what I told my sons when they took the trains. I said: I don't believe in this India-Shindia. It's all very well, you're going away now, but suppose when you get there, they decide to draw another line somewhere? What will you do then? No one will have you anywhere. As for me, I was born here, and I'll die here (Amitav Ghosh).

He even refuses the grandmother's proposal of going back to Calcutta. In this way, the old people live where their roots are founded. They are emotionally involved with their origin. So out of her love for her birth place grandmother Thamma crosses the lines between the two countries and visits her old house in Dhaka. As a consequence, the novel has the characters like grandmother Thamma or her old uncle who have been deeply rooted in their culture. Being deeply patriotic, Thamma thinks that a nation is formed on the sacrifices of its people. They are very much loyal and devoted to their own ideology irrespective of any opposition to it. That is why; they strictly oppose the behaviour against their own belief and conviction hence, she strongly revolts against the idea that her own motherland has become foreign now. The grandmother is a starch nationalist.

Thamma, who is very much national, believes in the legacy of her birth place called Dhaka which is the capital of Bangladesh, a neighbouring country of India now. According to her, the legacy of her birth place is not separable from her sense of being an Indian. Hence, the story of the novel centres on themes of nationality, diaspora, alienation, nostalgic feelings to the nation, and internationality, cultural and historical self-determination and this has been underlined by the title of the novel very significantly. It is because, the title is quite symbolic. Partition divided Hindustan into India and Pakistan. This division had been shocking to many people. But a good number of people in the period did not believe in such political and administrative division. It is because people had been thoroughly rooted in their origin. Therefore characters like grandmother succeed in maintaining their cultural, civilizational uniqueness. Rather, they consistently remember their roots. All this underscores the importance of diasporic identity, the novel has obtained in the course of time.

The novel portrays the depiction of the freedom movement in Bengal, the Second World War, the partition of India and the stink of communal hatred breaking out into riots in East Pakistan following the Hazratbal shrine incident in Srinagar in 1964. It has reflected the emotional and psychological trauma, not limited to a particular community, but across geographical boundaries. These are mere shadow lines that reveal the fragility of partition violence, borderline disputes and the catastrophic lines that claim to separate people and communities. Towards the later part, when the narrator recalls the newspaper report in 1964 describing the ghastly communal riots and curfew in Calcutta, he remarks "... Sitting in the air conditioned calm of an exclusive library that I began on my strangest journey: a voyage into a land outside space, an expanse without distances; a land of looking glass events" (Amitav Ghosh 247). The novel describes violence and riots at three different levels: one, between religious communities 
within one nation or state, two, riots between two states, and three, between different communities and the government. "There are no reliable estimates of how many people were killed in the riots of 1964. The number could stretch from several hundred to several thousand; at any rate not very many less than were killed in the war of 1962" (Amitav Ghosh 253).

Thamma's feelings of nationalism are related to her idealistic views about self-esteem, nostalgia, and the importance of national power. She does not like Ila's decision of staying in England. Thamma thinks only the British have earned the right to live in England because "it took those people a long time to build that country...years of years of war and bloodshed. Everyone who lives there has earned his right to be there with blood...War is their religion. That is what it takes to make a country" (Amitav Ghosh 77-78). According to Bhaduri "Nationalism, the product of those times, carries for her the creed of religion, and informs her thoughts and deeds" (Bhaduri 107). That is why; the English can enjoy the privilege guaranteed by their country. She feels that Indians have no right to live there and enjoy the facilities that they have not earned. Similarly, Thamma's uncle does not believe in displacement. He does not want to see himself in India. Thamma fails to change his mind. When she requests her uncle to leave his house for a better life in India, he makes a scathing attack on the notion of nationhood and nationalism. He says "I don't believe in India-Shindia..... I was born here and I'll die here" (Amitav Ghosh 215).

The novel has the idea of constant crossing and re-crossing or with rejection of borders and boundaries; this study aims to examine how they are treated in The Shadow Lines. Borders drawn out of some political interest affects the harmonious environment. This kind of division brings out nothing but wars, massacres, riots and unhappiness among the people. The Shadow Lines is not the only novel of Ghosh's to deal with borders. The notion of a borderless universe is clearly something that preoccupied Amitav Ghosh's novels. His appeal for a borderless universe and his penchant for recovering lost histories come together in The Shadow Lines. The novel takes up the challenge of representing the complexity of national identity.

The Shadow Lines is the Partition novel examined in this book that really questions the concept of the border, questions very seriously whether the shadow line that we inscribe to separate people into different nations has any validity, or whether it is an absurd illusion. It is Ghosh's contention in this novel that borders themselves are fictive and illusive, that they defeat and negate the very reason behind their ostensible existence. What Tridib's atlas demonstrates to the narrator, the lesson he learns after a harrowing seventeen year-long search for the truth of Tridib's death, is that in the ultimate analysis, borderlines do not mean anything at all. But beyond this, yet another interesting aspect of the The Shadow Lines is that it gives us a representation of the nation in both colonial and postcolonial times through characters who belong to three contiguous generations (Jethamoshai, Thamma and Robi); and it shows how the narrator, with the gift of vision bequeathed by Tridib, not only uncovers but also bridges all the earlier perspectives towards nationhood.

To sum up, Ghosh deals with the issues of alienation sufferings and nostalgic emotions, the representation of history and ultimately concludes that all borders are imaginary constraints. He dismantles history, the frontiers of nationality, culture and language. The novel is a manifestation of the desire to validate the postcolonial experience and to attempt a reconstruction of public history. The author asserts that the borders that separate nations are nothing more than artificial lines created by men. Thus, The shadow lines of the title are the borders that divide people, and one of the main emphases of the novel is on the arbitrariness of such cartographic demarcations. Ghosh believes that these shadow lines, these meaningless borders, can and should be crossed if not physically, then at least mentally through our imagination and through open minded acceptance of people, irrespective of nationality, religion or race.

Thus, the novel implicitly suggests the need for coexistence and strong humanitarian ties across cultures overlooking personal, regional and political considerations. It questions the meaning of political freedom and the force of nationalism in the modern world. It asks a very important, a universal question that what is a nation? What is this great entity that nationalism serves? Does it even exist? Should it exist? The novel is fundamentally portrays the Hindu-Muslim riots caused by Partition and rumours spread thereafter and consequently its evil effects on innumerable innocents. Due to this predicament, the characters are sent to various regions and areas where they are in search of their own identity. This exploration on their part has bestowed general Identity to the present novel. Ultimately, the characters cross their social, cultural, and national boundaries which have given a theme of nostalgia and alienated sufferings of displacement. The impact of partition shows that many people were killed in the name of religion and thousands of people who managed to cross the border lived their life as refugees. Nostalgia and alienation are the powerful theme in the novel that affects the life of the people, these express their grief and anger because of the impact of 
partition that demonstrate their alienation and nostalgic emotions.

\section{REFERENCES}

[1] Bose, Brinda. Amitav Ghosh: Critical Perspectives. Pen craft International, 2003.

[2] Bhaduri, Seema. Of Shadow Lines and Freedom, Novy Kapadia (editors.), The Shadow Lines: Critical Perspective (edition), Asia Book Club, Delhi. 2001.

[3] Ghosh, Amitav. The Shadow Lines. Ravi Dayal and Permanent Black, 1988.

[4] Jassal, S.T. and Ben-Ari, E. The Partition Motif: Concepts, Comparisons, and Considerations, Jassal, S.T. \& Ben-Ari, E (editors.), The Partition Motif in Contemporary Conflicts. (edition), Sage Publications, New Delhi/London. 2007.

[5] “Partition Literature." Keywords in Transcultural English S tudies. http://www.transcultural -englishstudies.de/partition-literature/. Web. 19 Apr. 2017.

[6] Said, Edward W. Culture and Imperialism. Vintage Books, 1994. 